\title{
ТЕРРИТОРИАЛЬНОЕ ПЛАНИРОВАНИЕ И КАЧЕСТВО ГОРОДСКОЙ СРЕДЫ
}

\begin{abstract}
Аннотация. В данном тексте предпринята попытка ответить на вопрос, как качество правового обеспечения прочесса территориального планирования воздействует на качество городской среды. Лишь то планирование можно считать хорошим, в документах которого содержится расчетное предвидение должного наступить в будущем результата - качества городской среды. Существуют профессиональные технологии такого расчетного предвидения. Они включают три компонента: (а) составление балансов между планируемыми объемами застройки и с ними соотнесенными объемами инфраструктуры (транспортной, социальной, инженерно-технической); (б) определение реальных финансовых возможностей такую инфраструктуру последовательно по этапам создавать, а затем (в) содержать инфраструктуру в определенном количественном объеме и на приемлемом уровне качества в пределах реальных финансовых возможностей бюджета и населения города. Если отсутствуют указанные положения, то генеральный план не может быть признан хорошим, а хорошим он может стать как минимум при том условии, что закон не препятствует выполнению указанных действий в прочессе территориального планирования. В данном тексте говорится о наличии таких законодательных препятствий и о необходимости их устранения. Речь пойдет о связи трех областей смыслов: 1) об универсальной логике территориального планирования при подготовке генеральных планов; 2) об антилогике федерального закона, номинально упразднивщего универсальную логику территориального планирования; 3) о последствиях проявления на практике ошибок федерального закона.
\end{abstract}

Ключевые слова: Территориальное планирование, Объемы застройки, Инфраструктура, Бюджет, Генеральный план, Федеральный закон, Правоприменение, Реализация, Ответственность, Градостроительный кодекс.

\section{1. Об универсальной логике} территориального планирования в отношении подготовки генеральных планов

T о, что такая логика существует, давно, неоднократно и неопровержимо доказано ${ }^{1}$ Но поскольку особенностью текущей ситуации для профессионального сообщества лиц, причастных к территориальному планированию, является то, что неопровержимо доказанное ныне уже как бы

\footnotetext{
${ }^{1}$ В том числе, в следующих публикациях: Э.К. Трутнев, Л.Е. Бандорин. Комментарий к Градостроительному кодексу Российской Федерации: ответы на проблемные вопросы градостроительной деятельности; Фонд «Институт экономики города». М.: Издательство «Экзамен», 2008. - 525 с. (книга доступна на сайте: http://www.urbaneconomics.ru/texts. php?folder_id=9\&mat_id=440\&page_id=14399); Э.К.Трутнев. Комментарий к Градостроительному кодексу Российской Федерации в части института территориального планирования, измененного Федеральным законом «О внесении изменений в Градостроительный кодекс Российской Федерации и отдельные законодательные акты Российской Федерации в части вопросов территориального планирования» от 20.03.2011 №41-Ф3 (комментарий доступен на сайте: http://www.urbaneconomics. ru/texts.php?folder_id=9\&mat_id=440\&page_id=14399).
}

не имеет доказательной силы по причине распространившегося агрессивного неведения, то придется еще раз кратко воспроизвести эту неупразднимую логику. Последовательно, шаг за шагом продвигаясь от одного положения к другому, приходим к искомому пониманию той области, которая имеет свои законы существования.

1.1. Область потенциальных возможностей развития города (А) всегда гораздо шире области реальных, то есть обеспеченных финансированием возможностей (Б).

1.2. Проявлением первой области возможностей (А) является пространство в виде многообразных вариантов освоения разных локальных городских территорий. Контуры этой области (А) могут определяться тремя основными позициями - принципиальными направлениями развития:

- первое направление развития: «давайте ограничимся лишь пределами уже застроенной территории, не будем выходить за эти предель, но будем обустраивать-облагораживать-дооформлять 
то, что хотя и считается как бы освоенным, но на самом деле остается весьма далеким от представлений о базовых стандартах качества городской среды»»;

- $\quad$ второе направление развития: «давайте оставим в покое застроенные территории (там уж очень накладно что-то реконструировать и преобразовывать) - давайте выйдем за их сковывающие предель и будем освачвать ныне свободные сопредельные с застройкой территории - будем создавать новые строительные площадки на новых территориях»;

- $\quad$ третье направление развития: «давайте вообще не будем принуждать себя к выбору, не будем себя ограничивать и не будем обременять себя предпочтениями - давайте как бы откажемся от выбора, будем одновременно обустраивать уже застроенную территорию и осваивать новые сопряженные территории без установления приоритета какого либо одного из этих двух направлений развития города: как случай распорядится, так тому и быть».

1.3. Проявлением второй области (Б) - области реальных, обеспеченных финансированием возможностей развития города - являются возможности совокупной городской инфраструктуры как существующей, так и создаваемой (транспортной, социальной, инженерно-технической) обеспечивать нормальное функционирование-использование застройки в ее соответствующих объемах, распределенных по соответствующим местам в городе. Особенности этой второй области (Б) реальных финансовых возможностей таковы:

- если случается, что первая область (А) не увязана соответствующей параметрической моделью со второй областью (Б), то генеральный план неизбежно обречен стать безответственной картинкой, отображающей лишь необязательное представление о будущем распределении застройки в лучшем случае, но чаще - документом, легализующим официальное одобрение начала фактически неуправляемых, деструктивных процессов «движения в разные стороны» (как это может происходить вопреки, якобы, добрым намерениям - см. ниже пункт 3.2);

- $\quad$ по причине того, что первая область (А) - пространство потенциального расширения застройки - всегда больше второй области (Б) - области текущих финансовых возможностей инфраструктурного обеспечения будущих объемов застройки, то неотвратимо возникает задача определить траектории движения к запланированному будущему - задача определить этапы последовательной реализации решений генерального плана (определить этапы как «порции»управляемого движения в будущее), то есть, определить динамику изменения баланса между застройкой и ее обслуживающей инфраструктурой;

- определение баланса между застройкой и ее обслуживающей инфраструктурой имеет две главные особенности;

- первая особенность: баланс должен быть комплексным в отношении учета всех видов параметров. Значения параметров локальных жилых образований (количество жилых единиц, количество домохозяйств, количество жителей и проч. )должны быть соотнесены со значениями параметров различных видов инфраструктуры. То есть, локальные жилые образования должны иметь полный комплект услуг в соответствии с представлениями о комплексности, соотнесенными с реальными возможностями обеспечивать приемлемый уровень комплексности - обеспечивать качество городской среды. Очевидно, что при ответственном планировании не могут возникать жилые образования без гарантирования со стороны власти создания такого минимального комплекта услуг - минимального качества городской среды ${ }^{2}$;

- вторая особенность: баланс должен быть сводом финансовых показателей в отношении двух видов бюджетных (по преимуществу) затрат на инфраструктуру - суммой (а) одноразовых бюджетных затрат на строительство и (б) ре-

\footnotetext{
${ }^{2}$ См. вопрос 39 - «Азбука градостроительного нормирования» в «Библиотеке ответов на вопросы о градостроительной деятельности»: http://www.urbaneconomics.ru/news/?mat_id=981
} 
гулярных-текущих бюджетных затрат (либо затрат, покрываемых тарифами - регулярными сборами с жителей города), постоянно направляемых на эксплуатацию построенных объектов инфраструктуры. Этот баланс, уже на стадии планирования составляемый, должен показать нечто принципиально важное: имеются, или отсутствуют для соответствующего направления развития(см. выше пункт 1.2)реальные финансовые возможности содержать-эксплуатировать инфраструктуру за счет лимитированных бюджетных средств и за счет тарифов, выплачиваемых гражданами, - тарифов, размеры которых также ограничены некими предельными возможностями населения платить за предоставляемые услуги. Указанные положения должны наглядно и конкретно демонстрировать то, что определяется распространенным, но содержательно обычно не раскрываемым (и, соответственно, плохо понимаемым) термином «устойчивое развитие города». Посредством этих расчетных положений по моделированию будущего города должен быть дан ответ на простой и честно поставленный вопрос: согласно принятому направлению развития будет ли город в состоянии оплачивать свое движение в будущее, будет ли он самообеспеченным образованием - будет ли город развиваться по восходящей траектории, либо будет обречен деградировать по причине предопределенного хронического недофинансирования инфраструктуры - будет деградировать, несмотря на возможное и желаемое наращивание объемов застройки во что бы то ни стало, но без должного комплекта инфраструктурного обеспечения- благодаря именно такому без инфраструктуры наращиванию объемов застройки (?).

1.4. Последнее обстоятельство указывает на наличие потенциальной опасности того, что планирование развития города может обернуться не планированием восходящего развития, но планированием нисходящего развития - «планированием деградации городской среды», несмотря на добрые намерения планировщиков и лиц, принимающих как бы ответственные реше- ния. Можно ли законом предотвратить «планирование деградации»? Если да, то, как это сделать?

Чтобы ответить на эти вопросы придется первоначально рассмотреть вопрос о том, понуждает ли федеральный закон рассчитывать и публично предъявлять указанные балансы, поскольку именно ония вляются единственным способом первоначально на уровне мышления предотвратить возможность возникновения безответственного планирования - планирования деградации городской среды.

\section{2. Об антилогике федерального закона, номинально упразднившего универсальную и неупразднимую логику территориального планирования}

2.1. Функция закона состоит в том, чтобы отграничить область неразумных действий от области разумных действий и принудить действовать в рамках последней. Только так закон сужает область хаоса и произвола - область распространения неразумия. Далее этого закон бессилен: поставив запрет на пребывание в области неразумного, закон уже не может гарантировать восхождение на следующую ступень разумности действий соответствующих субъектов управления. Отсюда начинается другая не подвластная закону область - область методологии, распространения рекомендаций и утверждения профессионального мастерства планировщиков, а также область разумения и мотиваций лиц, принимающих решения с учетом многообразия интересов и их противоречивости, а также последствий реализации принимаемых решений.

2.2. Итак, закон не всесилен. Тогда, каким образом закон может и должен заставить лиц, причастных к подготовке генерального плана, пребывать в области разумения - в той области, которая воспроизводит показанную выше универсальную и неупразднимую логику территориального планирования? Закон это может сделать посредством двух положений - суть императивных требований:

1) посредством требования о необходимости быть в составе утверждаемой части генерального плана ука- 
заниям о последовательности его реализации в виде соответствующих мероприятий и сроков. Очевидно, что сам факт наличия в законе такого требования, понуждает его выполнить, а выполнить его невозможно никаким иным способом, как только путем составления соответствующих расчетных балансов, о которых говорилось выше. Уже с этого места становится ясным, что невозможно не быть в генеральном плане выбору между различными направлениями развития. Из этого следует, что третье направление развития, утверждающее принципиальный отказ от выбора как предположение о возможности безнаказанно (без наступления негативных последствий) «плыть по воле волн» (см. пункт 1.2 - третье направление), недопустимо в силу логики самого процесса ответственного планирования. Однако же, это третье направление может и должно быть допущено к аналитическому рассмотрению только по одной причине - по причине субъективного характера, состоящей в достаточно широкой распространенности ошибочной позиции соответствующих субъектов управления, не желающих публично декларировать и утверждать непротиворечивый выбор и принимать на себя ответственность за последствия реализации именно выбранного направления развития;

2) посредством требования о необходимости быть некоему самостоятельному документу - комплексному (единому, сводному) плану реализации генерального плана. Необходимость быть такому самостоятельному документу определяется тем, что:

а) реализация всегда связана с процессом бюджетного планирования - с выделением соответствующих бюджетных средств на выполнение генеральным планом запланированных мероприятий;

б) бюджетное планирование - это всегда выбор приоритетов для финансирования (а приоритеты существуют по причине неизбывной разницы между желаемым-планируемым и реально возможным);

в) выбор приоритетов лишь тогда может состояться, когда в комплексном документе представлены все из множества различных возможностей и произведен из них обоснованный выбор в виде предложений в бюджет.
Очевидно, что такого рода самостоятельный комплексный (единый, сводный) документ в виде предложений в бюджет должен подготавливаться не реже одного раза в 2-3 года. Такова неустранимая логика технологического процесса планирования и реализации запланированного.

2.3. Указанные требования - это то необходимое, без чего институт территориального планирования как институт реального управления существовать не может.

И это необходимое в виде соответствующих требований содержалось до недавнего времени в Градостроительном кодексе Российской Федерации (далее также-ГрК РФ). Однако, указанный неопровержимый факт о невозможности допустить отсутствие необходимого не помешал другому федеральному закону сделать невозможное - упразднить необходимое-упразднить то, с упразднением чего фактически упраздняется институт реального территориального планирования, но при том, что номинально он еще не упраздняется (поскольку не упраздняются соответствующие словесные обозначения этого института в ГрК РФ). Речь идет о Федеральном законе «О внесении изменений в Градостроительный кодекс Российской Федерации и отдельные законодательные акты Российской Федерации в части вопросов территориального планирования» от 20.03.2011 №41-Ф3. Посредством этого закона упразднены требования относительно необходимости быть в самом генеральном плане указаниям о мероприятиях и этапах его реализации, а также упразднены комплексные планы реализации генеральных планов, совершены иные ошибки под знаком неоправданного «упрощения» института территориального планирования, а на самом деле - изъятия необходимого. Почему это произошло? Ответ на этот вопрос был доказательно предъявлен в свое время и в соответствующем тексте ${ }^{3}$.

\footnotetext{
${ }^{3}$ Более подробно об этом см. «Комментарий к Градостроительному кодексу Российской Федерации в части института территориального планирования»: http://www. urbaneconomics.ru/publications/?mat_id=126. В этом же Комментарии анализируются и иные ошибки №41-Ф3, как то: упразднение института зон планируемого размещения объектов, требующего установления соответствующих границ; упразднение института добровольного совместного территори-
} 
В данном же тексте стоит иная задача - раскрыть логику возникновения последствий от указанных ошибок и для федерального законодательства, и для практики территориального планирования на местах.

\section{3. О последствиях проявления на практике ошибок федерального закона}

3.1. Логика возникновения последствий для федерального законодательства достаточно проста: законодатели не любят признавать свои ошибки (включая ошибки, совершенные путем принятия №41-Ф3), поэтому допущенные ошибки, как правило, не исправляются, но вместо этого вносятся соответствующие дополнительные изменения, и подчас создается ситуация, когда прежние ошибки являются основанием для порождения новых ошибок, а положение дел еще более запутывается и ухудшается ${ }^{4}$.

3.2. В отношении практики территориального планирования на местах с принятием №41-Ф3 неотвратимо возникают следующие последствия:

- легализованная законом необязательность подготовки связей-балансов между областью потенциально возможных направлений развития (А) и областью реальных финансовых возможностей (Б) провоцирует появление «безразличных и безразмерных» генеральных планов, в которых могут утверждаться прямо противоположные, друг друга уничтожающие антагонистические направления развития (см. пункт 1.2 - третье направление). Утверждение таких генеральных

ального планирования; введение института «нефинансируемых мандатов» применительно к органам местного самоуправления, «понуждаемых к доделыванию» того, что не доделали органы государственной власти при территориальном планировании; освобождение государства от ответственности за принятые документы территориального планирования в части возмещения вреда в соответствующих случаях, иные ошибки.

${ }^{4}$ Примером является ситуация, когда федеральный законодатель, ошибочно «упростив» институт территориального планирования, приступил затем на основе предшествующих ошибочных упрощений к совершенствованию другого института - института планировки территории, подготовив соответствующий законопроект с многочисленными новыми ошибками концептуального характера. См. об этом вопрос 52 в «Библиотеке ответов на вопросы о градостроительной деятельности»: http:// www.urbaneconomics.ru/news/?mat_id=981 планов становится триггером процесса «падающего домино» - дает старт последующим процессам, которые, как правило, уже плохо контролируются управленцами, однажды вставшими на путь безразличного приятия всего без выбора и без разбора, - дает старт процессам, также имеющим свою неотвратимую логику развертывания, которая непременно будет воплощена в практику будущей жизни;

- $\quad$ то, что определено в «безразличном и безразмерном» генеральным плане, должно быть переведено и будет переведено в правила землепользования и застройки в виде градостроительных регламентов - основы правового режима использования земельных участков;

- градостроительные регламенты должны воспроизвести решения «безразличного» генерального плана -должны дать возможность по инициативе частных лиц и на основе предоставленных им прав осуществлять действия в противоположных, друг друга уничтожающих направлениях в части предъявления спонтанных запросов на обеспечение таких инициатив централизованной муниципальной инфраструктурой в разных местах города, которые оказываются не скоординированными друг с другом (по причине исходного отсутствия в генеральном плане мероприятий, которые были бы выстроены в виде временных и пространственных приоритетов);

- неизбежно возникнет возрастающее давление на власть со стороны нескоординированных запросов застройщиков в отношении обеспечения инфраструктурой (транспортной, социальной, инженерно-технической) спонтанно возникающей застройки, особенно в тех периферийных местах города, где располагаются земельные участки, заблаговременно приобретенные строительными фирмами для застройки, - земельные участки, для которых в нужное время под предусмотрительным давлением заинтересованных лиц было обеспечено «нужное зонирование с запасом» в безразличном генеральном плане, не выстроившем приоритетные, обеспеченные в финансовом отно- 
шении мероприятия по реализации «безразмерных решений» генерального плана;

- события могут первоначально развиваться благоприятно в статистическом смысле - в том смысле, что объемы застройки на периферийных территориях будут возрастать более высокими, чем ранее, темпами: первоначально всем будет явлен «статистический успех» - свидетельство как бы грамотного управления. Однако, в силу неизбывной несогласованности потребностей-пожеланий с реальными возможностями инфраструктурного обеспечения (несогласованности, предопределенной отсутствием расчетных балансов в самом генеральном плане - см. выше) даже и при таком первоначально благоприятном развитии событий неизбежно наступит момент времени, характеризуемый следующими особенностями: а) скорость прироста объемов застройки (прироста, достигаемого преимущественно освоением периферийных территорий) начнет все более и более отставать от скорости стремительного возрастания удельных затрат на содержание инфраструктурного обеспечения каждой единицы все более расширяющегося городского пространства; б) рост этих удельных затрат превысит некий порог финансовых возможностей горожан платить за содержание все более дорожающей инфраструктуры, и такое превышение будет продолжать увеличиваться по мере роста объемов периферийного строительства; в) наступление указанного превышения будет означать начало непредвиденного - начало восходящего процесса недофинансирования инфраструктурного обеспечения каждой единицы городского пространства, то есть, начало процесса прогрессирующей деградации городской среды. В этом состоит объективное проявление логики, неприятной для тех, кто отвергает необходимость совершать продуманный выбор направлений развития при осуществлении территориального планирования;

- таким образом, в случаях принятия «безразличных и безразмерных» генеральных планов высока вероятность того, что возникнет ситуация, когда стремление обеспечить лишь только хорошие статистические показатели роста объемов строительства спровоцирует необратимые процессы деградации городской среды. Очевидно, что это будет слишком дорогой платой за «статистическое благополучие» властных лиц, принимающих решения относительно развития города.

Таковы ловушки территориального планирования, а также неотвратимая логика планирования деградации городской среды - логика, которая всегда действует как бы врасплох - вопреки, казалось бы, добрым намерениям, если намерения не подкреплены соответствующими балансовыми расчетами.

На стадии территориального планирования фактически случившийся отказ от выбора четкого направления развития города, соотнесенного с реальными бюджетными ресурсами, то есть, отказ от продуманной концентрации сил, неизбежно приведет к нехватке ресурсов «на все и сразу» - к недофинансированию инфраструктуры, а значит - к деградации городской среды. Особенно остро эта неотвратимая логика проявит себя в тех городах России, где стабилизируется, либо сокращается население - где исчерпаны внутренние и межрегиональные ресурсы для демографического роста при одновременном наличии значительных свободных территорий, являющихся соблазном для «дешевого» многоэтажного строительства - для комплексного освоения частными застройщиками периферии города, а также для региональных и местных управленцев, готовых пойти на непросчитанные риски - готовых откликнуться на такие соблазны-инициативы частных застройщиков при том, что либо отсутствуют реальные финансовые возможности такие инициативы поддержать в отношении бюджетных затрат на инфраструктуру, либо такая поддержка может состояться за счет недопустимого небрежения должным уровнем инфраструктурного обслуживания населения в сложившихся центральных и срединных районах города, то есть, опять за счет снижения стандартов качества - за счет деградации городской среды ${ }^{5}$.

\footnotetext{
5 Эта универсальная логика не может не проявиться и уже проявляет себя. Одним из наиболее наглядных примеров реализа-
} 
Что же следует из всего сказанного? А следует то, что ошибки федерального законодателя порождают последствия в виде утверждения на практике опасных правовых механизмов, чреватых планированием деградации городской среды. Ошибки должны быть признаны и исправлены: в ГрК РФ должны быть возвращены положения, упраздненные из него посредством №41-Ф3, в том числе, генеральные планы вновь должны обрести мероприятия поэтапной реализации, должны быть возвращены в практику управления ком- плексные (сводные, единые) планы реализации генеральных планов как подготавливаемые на регулярной основе (не реже одного раза в 2-3 года)документы в виде предложений в соответствующие бюджеты.

Генеральным планам должен быть возвращен статус документов, принятие которых связано с ответственностью власти за их реализацию - с ответственностью, наличие которой предотвращало бы практику неосознанного планирования деградации городской среды.

\section{Библиография}

1. Э.К.Трутнев, Л.Е.Бандорин. Комментарий к Градостроительному кодексу Российской Федерации: ответы на проблемные вопросы градостроительной деятельности; Фонд «Институт экономики города». М.: Издательство «Экзамен», 2008. - 525 с.

2. Э.К.Трутнев. Комментарий к Градостроительному кодексу Российской Федерации в части института территориального планирования, измененного Федеральным законом «О внесении изменений в Градостроительный кодекс Российской Федерации и отдельные законодательные акты Российской Федерации в части вопросов территориального планирования» от 20.03.2011 №41-Ф3 (комментарий доступен на сайте: http:/www. urbaneconomics.ru/texts.php?folder_id=9\&mat_id=440\&page_id=14399)

3. «Азбука градостроительного нормирования» в «Библиотеке ответов на вопросы о градостроительной деятельности»: http://www.urbaneconomics.ru/news/?mat_id=981

4. «Комментарий к Градостроительному кодексу Российской Федерации в части института территориального планирования»: http://www.urbaneconomics.ru/publications/?mat_id=126.

5. «Библиотека ответов на вопросы о градостроительной деятельности»: http://www.urbaneconomics.ru/ news/?mat_id=981

ции ошибочных положений №41-Ф3, «освободившего» местную власть от ответственного территориального планирования (от утверждения балансов между желаемым и реально возможным), является Пермь, где в начале 2014 года были приняты изменения в генеральный план - изменения в идеологии отказа от выбора направления, связанного с концентрацией ресурсов во имя возрастания качества городской среды, в пользу принятия противоположного направления - «безразличного и безразмерного» генерального плана, способствующему реализации положений, ведущих к недофинансированию инфраструктуры, то есть, ведущих к постепенной деградации городской среды. Указанный пример требует, однако, отдельного аналитического исследования, а целью его проведения могло бы стать воспитание мышления у новой генерации профессионалов-урбанистов в отношении того, как и по каким причинам возникают ошибки и как должны предотвращаться такие ошибки в процессе ответственного территориального планирования. 


\section{References (transliterated)}

1. E.K.Trutnev, L.E.Bandorin. Kommentarii k Gradostroitel'nomu kodeksu Rossiiskoi Federatsii: otvety na problemnye voprosy gradostroitel'noi deyatel'nosti; Fond «Institut ekonomiki goroda». M.: Izdatel'stvo «Ekzamen», 2008. $-525 \mathrm{~s}$.

2. E.K.Trutnev. Kommentarii k Gradostroitel'nomu kodeksu Rossiiskoi Federatsii v chasti instituta territorial'nogo planirovaniya, izmenennogo Federal'nym zakonom «O vnesenii izmenenii v Gradostroitel'nyi kodeks Rossiiskoi Federatsii i otdel'nye zakonodatel'nye akty Rossiiskoi Federatsii v chasti voprosov territorial'nogo planirovaniya» ot 20.03.2011 №41-FZ (kommentarii dostupen na saite: http://www.urbaneconomics.ru/texts.php?folder_id=9\&mat_ $\mathrm{id}=440$ \&page_id=14399)

3. «Azbuka gradostroitel'nogo normirovaniya» $\mathrm{v}$ «Biblioteke otvetov na voprosy o gradostroitel'noi deyatel'nosti»: http://www.urbaneconomics.ru/news/?mat_id=981

4. «Kommentarii k Gradostroitel'nomu kodeksu Rossiiskoi Federatsii v chasti instituta territorial'nogo planirovaniya»: http://www.urbaneconomics.ru/publications/?mat_id=126.

5. «Biblioteka otvetov na voprosy o gradostroitel'noi deyatel'nosti»: http://www.urbaneconomics.ru/news/?mat id $=981$ 